\title{
APPLICATIONS OF THE HERMITE-HADAMARD INEQUALITY
}

\section{MONIKA NowickA AND AlfRed WitKowski}

Abstract. We show how the recent improvement of the Hermite-Hadamard inequality can be applied to some (not necessarily convex) planar figures and three-dimensional bodies satisfying some kind of regularity.

Mathematics subject classification (2010): 26D15, 26B15. lus.

Keywords and phrases: Hermite-Hadamard inequality, convex function, polygon, polyhedron, annu-

\section{REFERENCES}

[1] M. Bessenyei, The Hermite-Hadamard Inequality on Simplices, Amer. Math. Monthly 115, 4 (2008), 339-345.

[2] Y. CHEn, Multi-dimensional Hadamard's inequalities, Tamkang J. Math. 43, 1 (2012), 1-10.

[3] S. S. Dragomir and C. E. M. Pearce, Selected topics on Hermite-Hadamard inequalities and applications, RGMIA Monographs, Victoria University, Melbourne (2000), http://ajmaa.org/ RGMIA/monographs . php.

[4] J. HADAMARD, Étude sur les propriétés des fonctions entières et en particulier d'une fonction considérée par Riemann, J. Math. Pures Appl. 58, (1893), 171-215.

[5] P. C. Hammer, The midpoint method of numerical integration, Math. Mag. 31, (1958), 193-195.

[6] E. Neuman, Inequalities involving multivariate convex functions II, Proc. Amer. Math. Soc. 109, 4 (1990), 965-974.

[7] M. Nowicka And A. Witkowski, A refinement of the left-hand side of Hermite-Hadamard inequality for simplices, J. Inequal. Appl. (2015) 2015:373, DOI 10.1186/s13660-015-0904-0

[8] M. NowickA AND A. WiTKOWSKI, A refinement of the right-hand side of the Hermite-Hadamard inequality for simplices, Aequationes Math. (2016) DOI: 10.1007/s00010-016-0433-z

[9] J. PeČarić, F. Proschan And Y. L. Tong, Convex Functions, Partial Orderings, and Statistical Applications, Academic Press, Inc., 1992.

[10] S. WAsSOWICZ AND A. WitKowsKI, On some inequality of Hermite-Hadamard type, Opuscula Math. 32, 3 (2012), 591-600. 